\title{
Acute response to oral calcium loading in pregnant and lactating women with a low calcium intake: a pilot study
}

\author{
I. Schoenmakers • L. M. A. Jarjou • G. R. Goldberg • \\ K. Tsoi $\cdot$ D. Harnpanich $\cdot$ A. Prentice
}

Received: 20 August 2012 /Accepted: 21 January 2013 /Published online: 16 February 2013

(C) The Author(s) 2013. This article is published with open access at Springerlink.com

\begin{abstract}
Summary This pilot study in women from The Gambia with low habitual calcium intakes showed differences in calciotropic hormones between pregnant, lactating and nonpregnant, non-lactating women similar to those in Western women. The response to oral calcium loading indicates a high degree of calcium conservation independent of reproductive status.

Introduction In pregnancy and early lactation, parathyroid hormone (PTH) concentrations may be suppressed. Uncertainty exists about how calcium metabolism is regulated, particularly when calcium intake is low.

Methods We investigated fasting markers of calcium metabolism and the acute calcemic and calciuric responses after an oral calcium load in 30 pregnant, lactating or non-pregnant, non-lactating (NPNL) Gambian women with low habitual calcium intakes. Women received $1 \mathrm{~g}$ elemental calcium $\left(\mathrm{CaCO}_{3}\right)$ at $0 \mathrm{~min}$. Blood was collected at -30 and $180 \mathrm{~min}$. Urine was collected from -60 to $0,0-120$ and $120-240 \mathrm{~min}$. Samples were analysed (blood: ionized calcium (iCa); plasma (p): total calcium $(\mathrm{tCa})$, phosphate $(\mathrm{P})$, creatinine $(\mathrm{Cr}), \mathrm{PTH}$, 1,25-dihydroxyvitamin $\mathrm{D}\left(1,25(\mathrm{OH})_{2} \mathrm{D}\right)$, osteocalcin $(\mathrm{OC}), \beta$ $\mathrm{C}$-terminal cross-linked telopeptide of type 1 collagen $(\beta \mathrm{CTX})$, cyclic adenosine monophosphate (cAMP); urine (u): $\mathrm{Ca}, \mathrm{P}, \mathrm{Cr}, \mathrm{cAMP}$ ).
\end{abstract}

I. Schoenmakers $(\bowtie) \cdot$ G. R. Goldberg $•$ K. Tsoi • D. Harnpanich • A. Prentice

MRC Human Nutrition Research, Elsie

Widdowson Laboratory, Fulbourn Road,

Cambridge CB1 9NL, UK

e-mail: inez.schoenmakers@mrc-hnr.cam.ac.uk

L. M. A. Jarjou • G. R. Goldberg • A. Prentice

MRC Keneba, MRC Laboratories,

PO Box 273, Banjul, The Gambia
Results Pre-loading, groups did not differ significantly in $\mathrm{iCa}, \mathrm{pP}, \mathrm{uCa} / \mathrm{Cr}$ and $\mathrm{uP} / \mathrm{Cr}$. pOC concentrations were significantly lower and NcAMP and $\mathrm{p} 1,25(\mathrm{OH})_{2} \mathrm{D}$ higher in pregnant women; $\mathrm{pPTH}$ and $\mathrm{p} \beta \mathrm{CTX}$ in lactating women were higher than in NPNL women. Post-loading, iCa, ptCa and $\mathrm{uCa} / \mathrm{Cr}$ concentrations increased; $\mathrm{pPTH}, \mathrm{NcAMP}, \beta \mathrm{CTX}$ and $\mathrm{uP} / \mathrm{Cr}$ decreased in all groups, but the magnitude of change did not differ significantly between groups.

Conclusion Differences between pregnant, lactating and NPNL Gambian women in pPTH, NcAMP and p1,25(OH $)_{2} \mathrm{D}$ and bone markers were similar to Western women. However, the response to calcium loading indicates that there may be no differences in renal and intestinal calcium economy associated with reproductive status, potentially due to a high degree of calcium conservation associated with low intakes.

Keywords Calcium · Calcium excretion · Lactation · Parathyroid hormone $\cdot$ Phosphate $\cdot$ Pregnancy

\section{Introduction}

Adaptations in maternal calcium homeostasis and balance occur during late pregnancy and lactation to meet requirements for foetal bone mineralisation and calcium secretion into breast milk. In Western women, intestinal calcium absorption increases in pregnancy [1-3]. Little change in the maternal bone mineral status (bone mineral density or content) is observed, although an increase in bone remodelling is reported [3, 4]. During lactation, bone resorption and renal calcium conservation are increased in both Western and Gambian women with concomitant decreases in bone mineral status [1, 5-7]. Changes in maternal bone mineral status and bone resorption during pregnancy and lactation 
appear to be independent of calcium intake in populations with a wide range of habitual calcium intakes [3, 4].

Uncertainty exists about how maternal calcium metabolism and balance are regulated, particularly in women with very low calcium intakes. During pregnancy and early lactation, plasma PTH concentration (pPTH) is suppressed, but plasma 1,25-dihydroxyvitamin $\mathrm{D}\left(\mathrm{p} 1,25(\mathrm{OH})_{2} \mathrm{D}\right)$ is similar or elevated compared to non-pregnant, non-lactating women (NPNL) $[3,8,9]$. This may be explained partly by the increase in the plasma concentration of PTH-related peptide (PTHrP). The role of PTHrP in the regulation of maternal calcium and bone metabolism is unclear, however, as it does not appear to respond to changes in plasma calcium $[2,4$, 10], unlike PTH which remains responsive to changes in calcium metabolism during pregnancy and lactation despite its lower concentration [1,11]. Earlier studies in Australia and USA applied calcium-loading (or oral calciumtolerance) tests to investigate changes in calcium homeostasis in pregnant and lactating women with calcium intakes close to recommendations $[1,2]$. The calcium-loading test utilizes a single oral dose of calcium and is designed to test the response of the calciotropic hormones and calcium handling in the intestine and kidney to provide a proxy measure of the rate of calcium absorption and renal calcium excretion $[2,12]$. In this pilot study, we investigated the calcemic and calciuric responses to oral calcium loading in pregnant, lactating and NPNL rural Gambian women with a habitual calcium intake of $\sim 350 \mathrm{mg} /$ day. We aimed to provide pilot data to investigate adaptations in calcium homeostasis during the reproductive cycle in Gambian women and to investigate that there was an indication of the pattern of response to be different from women with a higher calcium intake in order to consider whether a larger study is warranted.

\section{Materials and methods}

\section{Subjects}

Healthy pregnant, lactating and non-pregnant, non-lactating (NPNL) women, ten in each group, were identified through the West Kiang database and were recruited in 2008 from the villages of Keneba, Manduar and Kanton Kunda, in West Kiang, The Gambia, West Africa. Subjects were matched for age and parity at inclusion. Trained fieldworkers explained the study in the participant's native language, and an informed written consent was obtained. Pregnant women were 30-36 weeks gestation, based on predicted date of delivery as estimated by a midwife after an ultrasound scan and the date of the last menstrual period, and was back tracked on the basis of the date of birth of the baby. Lactating women were 2-4 months post-partum based on the date of birth of their child and were demand breastfeeding. NPNL women reported to have recently had their menstrual period and were at least 3 months postlactation; the period of breastfeeding in this region is typically 18-24 months [7]. We did not collect information on the use of contraceptives as this is a sensitive issue in this community and would have been unlikely to result in accurate data. The study took place at the MRC Keneba Fieldstation in the wet season (June-September). The study was approved by the joint Gambian Government/MRC Ethics Committee, and the London School of Hygiene and Tropical Medicine Ethics Committee.

\section{Calcium-loading test}

The strictly standardized protocol was based on that used in pregnant, lactating and NPNL white Australian women by Kent et al. [1]. Women arrived between 0700 and 0800 hours after an overnight fast and were asked to empty their bladder 60 min prior to being given the calcium dose. This consisted of $1 \mathrm{~g}$ elemental calcium (given as two $\mathrm{CaCO}_{3}$ tablets; Calcichew, Shire Pharmaceuticals Ltd., UK). Water $(200 \mathrm{ml})$ was given every hour. Blood samples were taken $30 \mathrm{~min}$ before (pre-Ca) and $180 \mathrm{~min}$ after the calcium (postCa) dose. All urine produced between $60 \mathrm{~min}$ pre-Ca and baseline and from baseline to 120 and 240 min post-Ca was collected. All samples were collected within 5 min before or after the scheduled time). A small standardized meal (300 g of porridge, composed of $49 \mathrm{~g}$ millet flour, $230 \mathrm{ml}$ water, $1 \mathrm{~g}$ salt, 20 g sugar; composition: $780 \mathrm{~kJ}, 14 \mathrm{mg}$ calcium, $36 \mathrm{mg}$ phosphorus, $0.1 \mathrm{mg}$ phytates) was given $30 \mathrm{~min}$ post-Ca, and participants were requested to eat it all.

\section{Sample collections and laboratory analyses}

Blood samples were collected into pre-cooled lithium-heparin (LH) or EDTA tubes (S-Monovette, Sarstedt Ltd, Leicester, UK). The EDTA sample was placed on ice immediately. The LH whole blood sample was measured for ionized calcium (iCa; pH 7.4 corrected values), haemoglobin $(\mathrm{Hb})$ and $\mathrm{pH}$ within $10 \mathrm{~min}$ of collection (ABL77 blood gas analyser, Radiometer, Brønshøj, Denmark), and the remaining sample was then placed on ice. Plasma was separated within $1 \mathrm{~h}$ of collection in a refrigerated centrifuge at $1,800 \mathrm{~g}$ for $20 \mathrm{~min}$, and aliquots were stored at $-70{ }^{\circ} \mathrm{C}$.

Urine was collected in acid-washed containers, mixed thoroughly. Non-acidified and acidified (concentrated hydrochloric acid $(\mathrm{HCl}), 10 \mathrm{ml} / \mathrm{l}$, laboratory reagent grade, SG 1.18, Fisher Scientific) aliquots were taken and stored at $-20{ }^{\circ} \mathrm{C}$.

After completion of the study, plasma and urine samples were packed and shipped on dry ice to MRC Human Nutrition Research, Cambridge and subsequently stored at $-80{ }^{\circ} \mathrm{C}$ until analysis. 
LH plasma was used for the measurement of $1,25(\mathrm{OH})_{2} \mathrm{D}$ (radioimmunoassay IDS Ltd., Tyne and Wear, UK), 25-hydroxyvitamin D (25(OH)D), bonespecific alkaline phosphatase (BALP), osteocalcin (OC) (all chemiluminescent immunometric automated assays, CLIA; DiaSorin, Stillwater, MN, USA), $\beta$ C-terminal cross-linked telopeptide of type 1 collagen ( $\beta \mathrm{CTX}$ ) (ELISA, IDS Ltd., Tyne \& Wear, UK), cAMP (ELISA, R\&D Systems, Abington, UK), total calcium (tCa), phosphate $(\mathrm{P})$, creatinine $(\mathrm{Cr})$ and albumin $(\mathrm{Alb})$ (colorimetric methods, Kone Lab 20i clinical chemistry analyser platform, Kone Espoo, Finland). EDTA plasma was used for the measurement of PTH by immunoassay (Immulite, Siemens Healthcare Diagnostics Ltd, Camberley, UK).

Urinary $(\mathrm{u})$ calcium $(\mathrm{uCa})$, phosphate $(\mathrm{uP})$ and creatinine $(\mathrm{uCr})$ were measured in acidified urine (colorimetric methods, Kone Lab 20i, as above). Concentrations of uCa and uP were expressed as a ratio relative to $\mathrm{uCr}$ to adjust for urinary volume. Urinary cAMP was measured in non-acidified urine (ELISA, R\&D Systems, as above).

All assays except PTH (between-assay coefficient of variation $(\mathrm{CV}), 4.7 \%)$ were performed in duplicate. Assay performance was monitored using kit and in-house controls and under strict standardisation according to ISO 9001:2000. Quality assurance of 25(OH)D and $1,25(\mathrm{OH})_{2} \mathrm{D}$ assays were performed as part of the Vitamin D External Quality Assessment Scheme (www.deqas.org) and PTH assays as part of the National External Quality Assessment Scheme (www.ukneqas.org.uk), and all were within accepted limits.

Within- and between-assay CVs for $1,25(\mathrm{OH})_{2} \mathrm{D}$ were 7.5 and $9.0 \%$. Cross-reactivity of the assay is 100 and $91 \%$ for $1,25(\mathrm{OH})_{2} \mathrm{D}_{3}$ and $1,25(\mathrm{OH})_{2} \mathrm{D}_{2}$, respectively. Cross-reactivity of the $25(\mathrm{OH}) \mathrm{D}$ assay is 100 and $104 \%$ for $25(\mathrm{OH}) \mathrm{D}_{3}$ and $25(\mathrm{OH}) \mathrm{D}_{2}$, respectively. Within- and between-assay CVs were 3.7 and 2.9, 1.6 and 3.6, and 3.8 and $4.0 \%$ for $25(\mathrm{OH}) \mathrm{D}$, BALP and $\mathrm{OC}$, respectively. The within- and between-assay CVs for $\beta$ CTX were 2.9 and $1.4 \%$. Within- and between-assay CVs for all Kone assays were $<2$ and $<4 \%$, respectively. Within- and between-assay CVs for pcAMP and ucAMP were 6.0 and $4.8 \%$.

Statistics, data handling and derived variables

Data processing and statistics were performed using Microsoft Excel 2010 (Microsoft Corp., Seattle, WA, USA) and Linear Model Software in Data Desk 6.0 (Data Description, Inc., Ithaca, NY, USA). Non-normally distributed data were transformed to natural logs. Within- and between-group differences were analysed with ANOVA or ANCOVA as appropriate, with Scheffé post-hoc tests. The absolute change in each analyte was examined to investigate the response to calcium loading. The level of significance was set at $P \leq 0.05$. Because of the small numbers of participants, $P$ values $\leq 0.10$ are also reported to indicate possible trends in the data.

The following variables were derived:

$$
\begin{aligned}
& \text { Albumin-corrected calcium }(\mathrm{pCaAlb}=\mathrm{ptCa}+[(40-\mathrm{Alb} \\
& (\mathrm{g} / \mathrm{L})) \times 0.02])[13,14] \text {. } \\
& \text { The fractional excretion of calcium }(\mathrm{Ca}= \\
& (\mathrm{uCa} / \mathrm{uCr}) \times \mathrm{pCr}) \text { and of } \mathrm{P}\left(\mathrm{P}_{\mathrm{e}}=(\mathrm{uP} / \mathrm{uCr}) \times \mathrm{pCr}\right)[2] . \\
& \text { Nephrogenic cAMP }(\mathrm{NcAMP}=(\mathrm{ucAMP}-\mathrm{pcAMP}) \times \\
& (\mathrm{pCr} / \mathrm{uCr}))[14] \\
& \text { The renal calcium threshold }(\mathrm{TmCa} / \mathrm{GFR}=[(0.56 \times \\
& \left.\left.\left.\mathrm{pCa})-\mathrm{Ca} \mathrm{a}_{\mathrm{e}}\right] /\left[1-0.08 \log _{\mathrm{e}}(0.56 \times \mathrm{pCa}) / \mathrm{Ca} \mathrm{a}_{\mathrm{e}}\right)\right]\right) . \\
& \text { The renal threshold for phosphate }(\mathrm{TmP} / \mathrm{GFR})= \\
& \mathrm{TRP} \times \mathrm{pP}, \text { if TRP } \leq 0.86 . \text { If TRP }>0.86, \mathrm{TmP} / \mathrm{GFR}=\alpha \times \\
& \mathrm{pP} . \mathrm{TRP}=1-[(\mathrm{uP} / \mathrm{pP}) \times(\mathrm{pCr} / \mathrm{uCr})] \text { and } \alpha=0.3 \times \\
& \mathrm{TRP} /[1-(0.8 \times \mathrm{TRP})] \text { as described by Payne }[15] .
\end{aligned}
$$

For the calculation of albumin-corrected calcium, different equations $[13,16,17]$ and group-specific equations, as based on regression analyses, were used because the albumin-calcium relationships may differ between populations and reproductive stages. Bland-Altman analyses [18] showed no significant differences between the values calculated according to different methods. Further, regression analyses of the calciumalbumin relationship showed no significant group interaction $(P=0.4)$. Therefore, the Payne equation $[13,16]$ was used for further analyses. The dataset contained one outlier in $\mathrm{Ca}_{\mathrm{e}}$ in the pregnant group as detected by standard procedures (Data Desk 6.0), and this value was excluded from analyses, but its inclusion made no material difference to the conclusions drawn.

We aimed to be able to detect a difference of $1.5 \mathrm{SD}$ between groups with a sample size of $n=10$ per group. A formal power calculation could not be performed for this study as the mean and distribution of most of the measured biochemical parameters are known to be markedly different from those in Western populations, and no data for the response to calcium loading are available in this population.

\section{Results}

Subject characteristics and baseline data

Subject characteristics are given in Table 1. Age, height, parity and weight were not significantly different between groups. Concentrations of $\mathrm{pAlb}, \mathrm{pCr}, \mathrm{Hb}$ and $\mathrm{ptCa}$ were significantly lower in pregnant women than in lactating and NPNL women. There were no significant group differences in ptCa when corrected for pAlb, or in p25(OH)D, 
Table 1 Subject characteristics and baseline values of markers of calcium, phosphate and bone metabolism

\begin{tabular}{|c|c|c|c|}
\hline & $\begin{array}{l}\text { Pregnant } \\
n=10\end{array}$ & $\begin{array}{l}\text { Lactating } \\
n=10\end{array}$ & $\begin{array}{l}\text { Non-pregnant, non-lactating } \\
n=10\end{array}$ \\
\hline \multicolumn{4}{|l|}{ Subject characteristics } \\
\hline Age (years) & $29.7 \pm 2.2$ & $27.3 \pm 2.0$ & $27.6 \pm 2.2$ \\
\hline Weight (kg) & $62.5 \pm 3.6$ & $59.4 \pm 2.8$ & $55.8 \pm 2.4$ \\
\hline Height (m) & $1.62 \pm 0.02$ & $1.65 \pm 0.01$ & $1.59 \pm 0.02$ \\
\hline Parity & $4.6 \pm 0.8(1-8)^{1}$ & $3.6 \pm 0.78(1-7)^{1}$ & $3.0 \pm 0.9(0-7)^{1}$ \\
\hline Gestation/post-partum (weeks) & $32.6 \pm 0.5$ & $14.2 \pm 0.20$ & - \\
\hline $\mathrm{pCr}(\mathrm{mmol} / \mathrm{L})$ & $59.2 \pm 1.5^{\mathrm{NL}}$ & $70.3 \pm 2.9$ & $74.0 \pm 2.5$ \\
\hline pAlb (g/L) & $25.5 \pm 0.8^{\mathrm{NL}}$ & $36.7 \pm 0.91$ & $34.1 \pm 0.65$ \\
\hline $\mathrm{Hb}(\mathrm{g} / \mathrm{L})$ & $11.2 \pm 0.38^{\mathrm{NL}}$ & $13.2 \pm 0.57$ & $13.0 \pm 0.35$ \\
\hline p25(OH)D (nmol/L) & $59.7 \pm 3.8$ & $63.2 \pm 5.1$ & $70.4 \pm 4.6$ \\
\hline \multicolumn{4}{|l|}{ Markers of renal mineral handling } \\
\hline TmCa/GFR (mmol/L GFR) & $2.31 \pm 0.20$ & $2.39 \pm 0.15$ & $2.15 \pm 0.15$ \\
\hline TmP/GFR (mmol/L GFR) & $1.25 \pm 0.06$ & $1.42 \pm 0.08$ & $1.18 \pm 0.09$ \\
\hline
\end{tabular}

Values are given as mean $\pm \mathrm{SE}$ or when indicated ${ }^{1}$ as range (min-max)

$\mathrm{Cr}$ creatinine, $\mathrm{Hb}$ haemoglobin, 25(OH)D 25(OH) vitamin D, $p$ plasma, TmCa/GFR the renal calcium threshold, TmP/GFR the renal threshold for phosphate

Letters are used to indicate

significant between-group differences in baseline values as tested by ANOVA/Scheffé $(P \leq 0.05)$; $N$ significantly different to

non-pregnant and non-lactating women; $L$ significantly different to lactating women

iCa, pP, uCa/Cr, uP/Cr, TmCa/GFR, TmP/GFR, $\mathrm{Ca}_{\mathrm{e}}$ and $\mathrm{P}_{\mathrm{e}}$ (Table 1; Figs. 1-3). The p1,25(OH) $)_{2} \mathrm{D}$ concentration was significantly higher and pOC and BALP (tendency) lower in pregnant than in lactating and NPNL women. In pregnant women, pPTH was lower compared to lactating women, and NcAMP was higher than in NPNL women. In lactating women, pPTH, p1,25(OH $)_{2} \mathrm{D}$ and $\mathrm{p} \beta \mathrm{CTX}$ concentrations were or tended to be $(P \leq 0.1)$ higher than in NPNL women (Table 1; Figs. 1-3).

There was a consistent pattern of $\mathrm{uCa} / \mathrm{Cr}, \mathrm{Ca}_{\mathrm{e}}$ and $\mathrm{P}_{\mathrm{e}}$ to be lower in pregnant and lactating than in NPNL and of pP, $\mathrm{uP} / \mathrm{Cr}$ and $\mathrm{TmP} / \mathrm{GFR}$ to be higher in pregnant women, although this did not reach statistical significance.

\section{Post-Ca loading}

Concentrations of $\mathrm{iCa}$ and $\mathrm{ptCa}$ significantly increased and $\mathrm{pPTH}, \mathrm{NcAMP}$ and $\mathrm{p} \beta \mathrm{CTX}$ decreased in all groups (Figs. 1-3). Only in pregnant women was there a significant decrease in $\mathrm{pP}$ and an increase in $\mathrm{p} 1,25(\mathrm{OH})_{2} \mathrm{D}$. In lactating women, pOC decreased. No differences were found in the plasma concentration of BAP possibly due to its long half-life. In all groups, $\mathrm{uCa} / \mathrm{Cr}$ significantly increased and $\mathrm{uP} / \mathrm{Cr}$ decreased from 120 to $240 \mathrm{~min}$ post-loading. This was paralleled by a significant increase in TmP/GFR and decrease in $P_{e}$ in all groups. TmCa/GFR decreased and $\mathrm{Ca}_{\mathrm{e}}$ increased only in pregnant women. The magnitude of change did not differ significantly between groups for any of the analytes in blood and urine.

Relationships between the increases in ptCaAlb and in $\mathrm{Ca}_{\mathrm{e}}$ and $\mathrm{pP}$ and $\mathrm{P}_{\mathrm{e}}$ are shown in Fig. 2c, d. Significant increases in $\mathrm{Ca}_{\mathrm{e}}$ per unit of ptCaAlb were found in pregnant women only. Significant decreases in $\mathrm{P}_{\mathrm{e}}$ per unit of $\mathrm{pP}$ were found in all groups.

\section{Discussion}

This pilot study showed that in pregnant Gambian women with a low calcium intake, NcAMP and $\mathrm{p} 1,25(\mathrm{OH})_{2} \mathrm{D}$ were higher, and bone formation was lower than in NPNL women. There was no evidence for pregnancy-induced absorptive hypercalciuria. In lactating women, $\mathrm{pPTH}$ and bone resorption were higher and $\mathrm{p} 1,25(\mathrm{OH})_{2} \mathrm{D}$ tended to be higher. Pregnant, lactating and NPNL women responded in a similar way and to a similar extent to calcium loading. This may indicate that pregnant, lactating and NPNL women from The Gambia may have similar rates of intestinal calcium absorption and extent of renal calcium conservation. The physiological changes in calcium and bone metabolism occurring in pregnancy and lactation may not lead to increases in calcium conservation.

These findings differ from those reported in pregnant and lactating women with calcium intakes close to Western recommendations $[1,2]$. Those studies showed a greater 

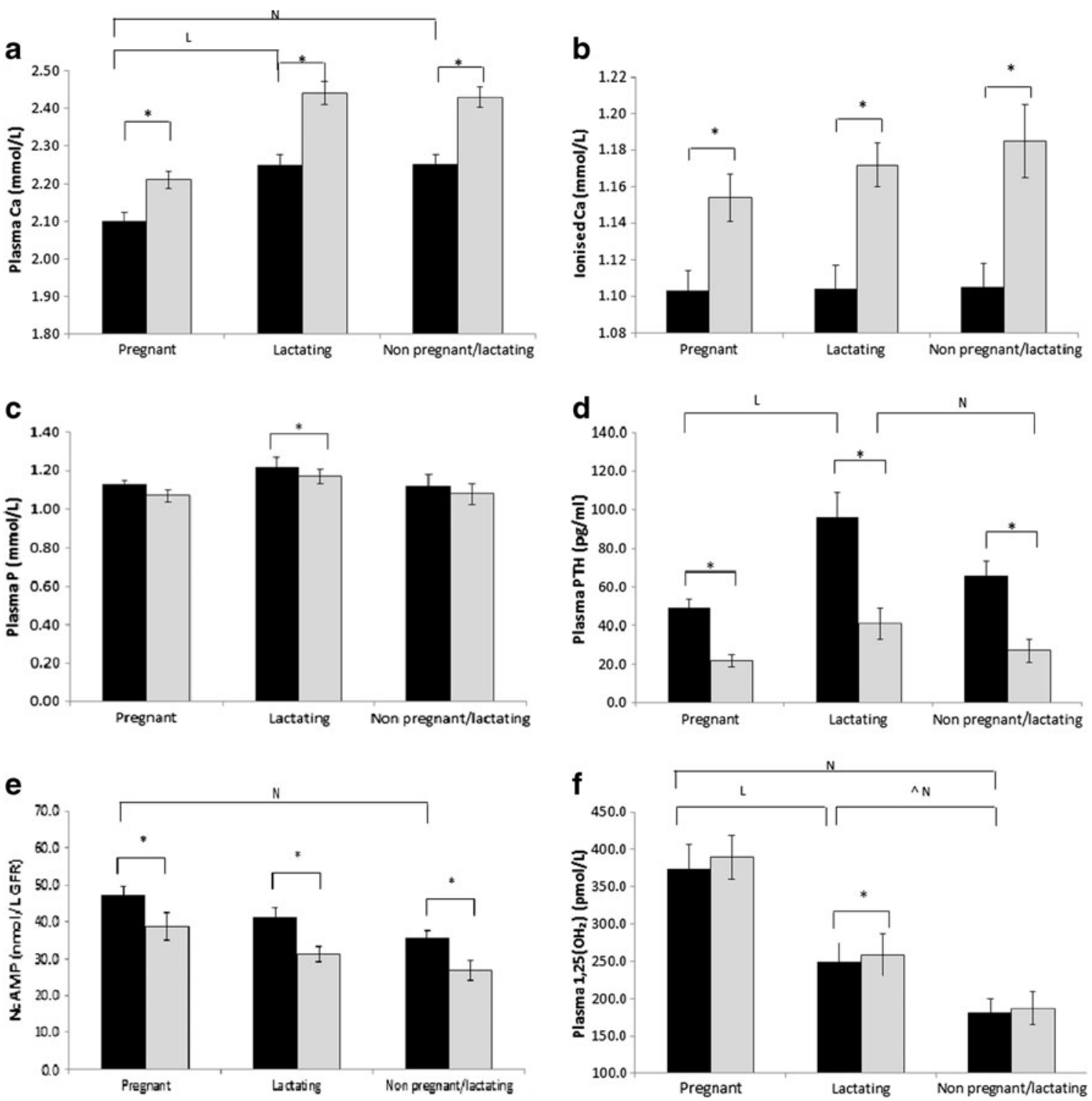

Fig. 1 Baseline (black) and response (grey) of total plasma calcium $(\mathrm{Ca} ; \mathbf{a})$, ionized $\mathrm{Ca}(\mathbf{b})$, phosphate $(\mathrm{P} ; \mathbf{c})$, parathyroid hormone $(\mathrm{PTH}$; d), nephrogenic cAMP (NcAMP; e) and 1,25-dihydroxy vitamin D $\left(1,25(\mathrm{OH})_{2} \mathrm{D} ; \mathbf{f}\right)$ to calcium loading in pregnant, lactating and nonpregnant and non-lactating women. Data are presented as mean $+\mathrm{SE}$. Asterisk is used to indicate significant within-group differences compared to baseline as tested with paired $t$ tests. Letters are used to

indicate significant between-group differences in baseline values as tested by ANOVA/Scheffé $(P \leq 0.05) ; N$ significantly different to nonpregnant and non-lactating women; $L$ significantly different to lactating women. Circumflex accent tendency to be significantly different as tested by ANOVA/Scheffé $(P \leq 0.10)$; No significant between-group differences in the change of any of these analytes were found

response in $\mathrm{ptCa}, \mathrm{iCa}$ and urinary calcium excretion in pregnant women, whereas lactating women showed a lower post-loading calcium excretion. These responses are indicative of an up-regulation of intestinal calcium absorption and renal reabsorption of calcium, respectively $[2,12]$. However, further studies specifically designed to assess calcium economy in the intestine and kidney are needed to confirm these findings.

The differences in the response to calcium loading and results of our previous studies of pregnant and lactating

women from The Gambia may indicate that the adaptations in calcium homeostasis may be different for Western and Gambian women. On theoretical grounds and as shown in our earlier studies in this population [19], it may be expected that with a calcium intake of $\sim 350 \mathrm{mg} /$ day, calcium absorption and renal calcium reabsorption are near their physiological maximum to meet the requirements for obligatory calcium losses in urine and faeces and, additionally during the reproductive cycle, for foetal skeletal mineralisation, secretion into breast milk ( $200-300 \mathrm{mg} /$ day) and post- 

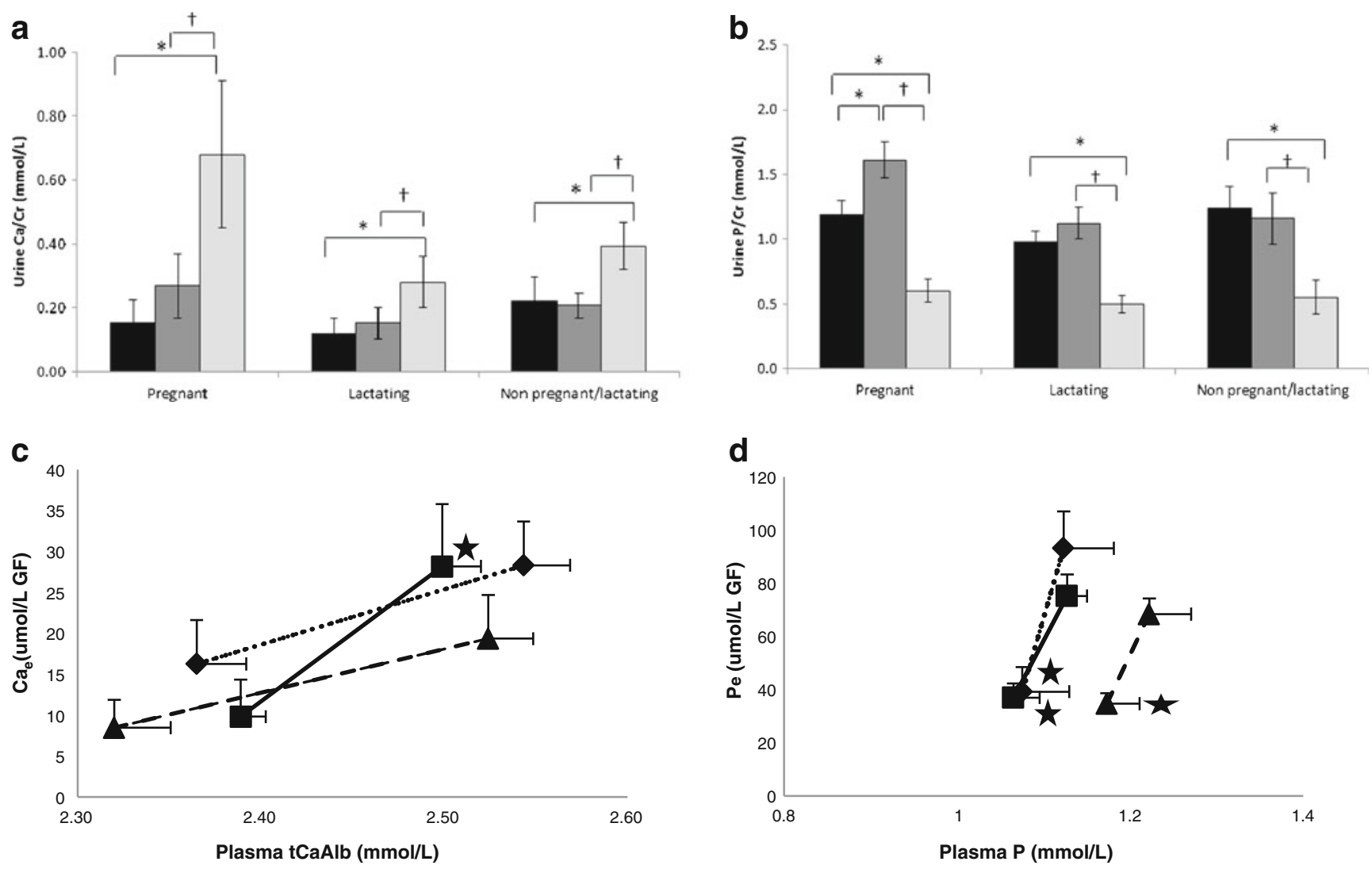

Fig. 2 Response in renal excretion of calcium (urine $\mathrm{Ca}$; a) and phosphate (urine $\mathrm{P}$; b) expressed as a ratio to urinary creatinine $(\mathrm{Cr})$ to $\mathrm{Ca}$ loading in pregnant, lactating and non-pregnant and non-lactating women. Relationships between the response in albumin-corrected plasma calcium (ptCaAlb) and fractional $\mathrm{Ca}$ excretion $\left(\mathrm{Ca}_{\mathrm{e}}\right)$ and plasma $\mathrm{P}$ (pP) and fractional $\mathrm{P}$ excretion $\left(\mathrm{P}_{\mathrm{e}}\right)$ are shown in $\mathbf{c}$ and $\mathbf{d}$. Symbols are used to indicate pregnant (black square), lactating (black triangle) and

lactational maternal bone mineral accretion [3]. This is underpinned by the low urinary calcium losses in Gambian NPNL and pregnant women shown in this study and other studies in this population [7], and by the absence of or only a moderate decrease in, urinary calcium losses during lactation as measured in $24 \mathrm{~h}$, fasting and post-loading urine collections (this study; [7]).

An alternative explanation for the absence of differences in the calcemic response between reproductive stages is the length of lactation (up to 2 years) and the typically short interval between cessation of lactation and next conception in this population [7]. The NPNL women in this study may therefore be in a different physiological state than those women included in other reports $[1,2]$ and may have a greater or more prolonged rate of calcium incorporation into the maternal skeleton in response to cessation of lactation. The three groups were matched for age and parity, and the NPNL women were eumenhorreic. It is, therefore, unlikely that the findings of the study reflect biological differences in the ability to conceive.

non-pregnant and non-lactating women (black diamond). Asterisk is used to indicate significant within-group differences compared to baseline (pre-Ca) and cross compared to 120 min post-Ca as tested with paired t-tests. Data are presented in mean + SE. No significant between-group differences in the change of any of these analytes were found. Further explanations of symbols and abbreviations used are described in Fig. 1

Despite the apparent moderate differences in calcium homeostasis between pregnant and lactating Gambian women compared to the differences seen in Western women, our earlier studies have shown that the changes in bone mineral status in lactating Gambian mothers at 13 weeks postpartum are similar to those reported for breastfeeding mothers with higher calcium intakes [5, 7]. This is consistent with other findings that dietary calcium intake is not a predictor of the changes in maternal bone mineral status associated with lactation [3, 4]. The conservation of bone mineral may be partly explained by the lower calcium outputs in breast milk, as mean milk calcium concentrations from Gambian women are lower than those of British women [7, 20, 21]. Together with a high degree of renal calcium conservation during both pregnancy and lactation, a decrease in bone formation during pregnancy and an increase in bone resorption during lactation $[5,7]$, these adaptations may be sufficient to meet the calcium requirements for foetal skeletal mineralisation and transfer in breast milk amongst Gambian women. 

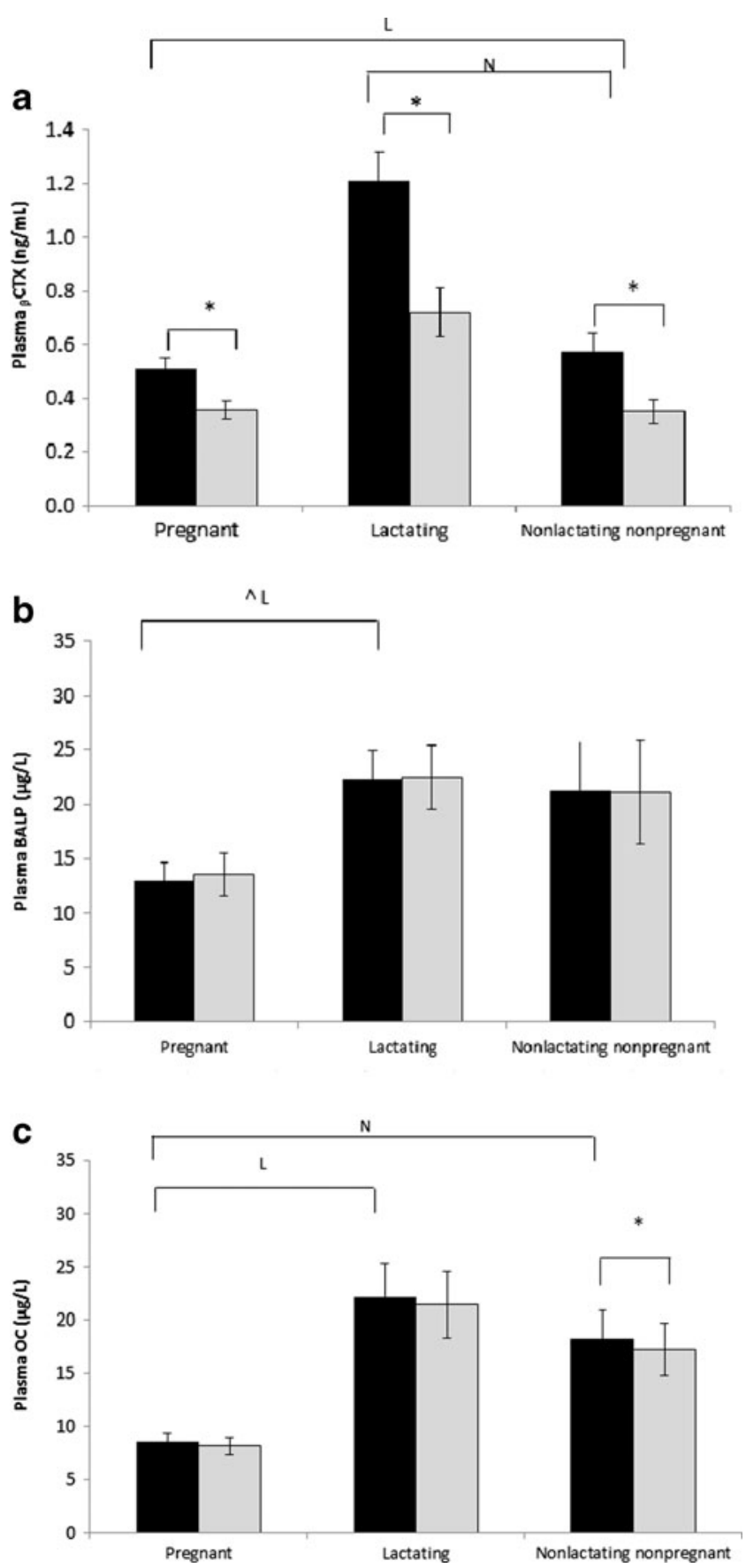

Fig. 3 Response of plasma markers of bone resorption (beta C-terminal cross-linked telopeptide of type 1 collagen $(\mathrm{p} \beta \mathrm{CTX}$; $\mathbf{a})$ and formation (bone-specific alkaline phosphatase (BALP; b) and osteocalcin $(\mathrm{OC} ; \mathbf{c}))$ to calcium loading in pregnant, lactating and non-pregnant and non-lactating women. Data are presented as mean + SE. No significant between-group differences in the change of any of these analytes were found. See Fig. 1 for further explanation of symbols used

In all groups, plasma PTH was relatively high. This is a common finding in this population and is likely to be due to their low calcium and high phytate intake [7, 17, 22]. In parallel to findings in Western women, NcAMP was relatively high for its concurrent plasma PTH concentration in pregnant Gambian women, but both did respond significantly to an acute calcium load. This suggests that, as in Western women, the parathyroid gland in Gambian women adapted to a low calcium intake is responsive to change in plasma calcium, but that other regulatory factors such as PTHrP are involved in calcium and phosphate metabolism during pregnancy.

There are several limitations of this study. Firstly, it included only ten women per group, and calcium-loading tests were performed on a cross-sectional basis. This will have limited the power of the statistical analyses and conclusions about changes that might be expected within individuals. In addition, during pregnancy, expansion of the plasma volume may have confounded the observed response particularly of plasma calcium in this and previous studies. This may only partly be corrected for by the use of ptCaAlb.

Comparability to the work by Gertner et al. [2] and Kent et al. [1] may be limited due to small differences between protocols. Gertner et al. [2] investigated women after 1 week on a standardized diet of $800 \mathrm{mg}$ calcium per day. In addition, in the studies performed by Kent et al. [1] and Gertner et al. [2], no breakfast was reported as given during the course of the calcium-tolerance test. The breakfast given in this study, although small and low in fat, protein, phytate, calcium and phosphorus content, may have influenced the post-loading response due to a delay in gastric emptying.

In conclusion, there were differences in $\mathrm{PPTH}, \mathrm{NcAMP}$ and $\mathrm{p} 1,25(\mathrm{OH})_{2} \mathrm{D}$ and bone markers between pregnant, lactating and NPNL Gambian women adapted to a low calcium intake similar to those described in Western women. There was no evidence of pregnancy-induced absorptive hypercalciuria as observed in Western women with higher calcium intakes. The response to calcium loading indicates that there may be no differences in renal and intestinal calcium economy between pregnant, lactating and nonpregnant, non-lactating women, potentially due to a high degree of calcium conservation associated with low intakes. Larger studies designed to assess calcium economy in the intestine and kidney are required to confirm these findings.

Acknowledgments This study was supported by the UK Medical Research Council under Programmes U105960371 and U123261351. Ms Tsoi was in receipt of a travel award from The Nestlé Foundation. We thank the staff of MRC Keneba, The Gambia for their help with this study. Specifically, we would like to thank Fabakary Bajo and Lamin Jammeh for performing the fieldwork, Sophie Moore, Head of Station, for accommodating the project and providing local support, Kerry Jones for advice on sample processing and ionized calcium measurements and Janet Bennett, Ann Laidlaw and Shailja Nigdikar, MRC Human Nutrition Research, for the laboratory analyses. This work was supported by the UK Medical Research Council (Programme numbers U105960371 and U123261351). The Nestlé Foundation awarded a student travel grant for Ms Tsoi. 


\section{Conflicts of interest None}

Open Access This article is distributed under the terms of the Creative Commons Attribution Noncommercial License which permits any noncommercial use, distribution, and reproduction in any medium, provided the original author(s) and the source are credited.

\section{References}

1. Kent GN, Price RI, Gutteridge DH, Allen JR, Blakeman SL, Bhagat CI, St John A, Barnes MP, Smith M, Evans DV (1991) Acute effects of an oral calcium load in pregnancy and lactation: findings on renal calcium conservation and biochemical indices of bone turnover. Miner Electrolyte Metab $17: 1-7$

2. Gertner JM, Coustan DR, Kliger AS, Mallette LE, Ravin N, Broadus AE (1986) Pregnancy as state of physiologic absorptive hypercalciuria. Am J Med 81:451-456

3. Olausson H, Goldberg G, Laskey M, Schoenmakers I, Jarjou L, Prentice A (2012) Calcium and bone metabolism in human pregnancy and lactation. Nutr Res Rev 25:40-67

4. Kovacs CS (2011) Calcium and bone metabolism disorders during pregnancy and lactation. Endocrinol Metab Clin North Am 40:795-826

5. Jarjou LM, Laskey MA, Sawo Y, Goldberg GR, Cole TJ, Prentice A (2010) Effect of calcium supplementation in pregnancy on maternal bone outcomes in women with a low calcium intake. Am J Clin Nutr 92:450-457

6. Olausson H, Laskey MA, Goldberg GR, Prentice A (2008) Changes in bone mineral status and bone size during pregnancy and the influences of body weight and calcium intake. Am J Clin Nutr 88:1032-1039

7. Prentice A, Jarjou LM, Cole TJ, Stirling DM, Dibba B, Fairweather-Tait S (1995) Calcium requirements of lactating Gambian mothers: effects of a calcium supplement on breastmilk calcium concentration, maternal bone mineral content, and urinary calcium excretion. Am J Clin Nutr 62:58-67

8. Kovacs CS (2011) Bone development in the fetus and neonate: role of the calciotropic hormones. Curr Osteoporos Rep 9:274-283

9. Brannon PM, Picciano MF (2011) Vitamin D in pregnancy and lactation in humans. Annu Rev Nutr 31:89-115
10. Simmonds CS, Kovacs CS (2010) Role of parathyroid hormone $(\mathrm{PTH})$ and $\mathrm{PTH}-$ related protein $(\mathrm{PTHrP})$ in regulating mineral homeostasis during fetal development. Crit Rev Eukaryot Gene Expr 20:235-273

11. Kalkwarf HJ, Specker BL, Ho M (1999) Effects of calcium supplementation on calcium homeostasis and bone turnover in lactating women. J Clin Endocrinol Metab 84:464-470

12. Broadus AE (1981) Nephrogenous cyclic AMP. Recent Prog Horm Res 37:667-701

13. Payne RB, Barth JH (1996) Adjustment of serum total calcium for albumin concentration: values change with age in women but not in men. Ann Clin Biochem 33(Pt 1):59-62

14. Tietz NW, Finley PR, Pruden E, Amerson AB (1990) Clinical guide to laboratory tests. Saunders, Philadelphia

15. Payne RB (1998) Renal tubular reabsorption of phosphate (TmP/ GFR): indications and interpretation. Ann Clin Biochem 35(Pt 2):201-206

16. Barth JH, Fiddy JB, Payne RB (1996) Adjustment of serum total calcium for albumin concentration: effects of non-linearity and of regression differences between laboratories. Ann Clin Biochem 33(Pt 1):55-58

17. Aspray TJ, Yan L, Prentice A (2005) Parathyroid hormone and rates of bone formation are raised in perimenopausal rural Gambian women. Bone 36:710-720

18. Bland JM, Altman DG (1986) Statistical methods for assessing agreement between two methods of clinical measurement. Lancet $1: 307-310$

19. Fairweather-Tait S, Prentice A, Heumann KG, Jarjou LM, Stirling DM, Wharf SG, Turnlund JR (1995) Effect of calcium supplements and stage of lactation on the calcium absorption efficiency of lactating women accustomed to low calcium intakes. Am J Clin Nutr 62:1188-1192

20. Laskey MA, Prentice A, Shaw J, Zachou T, Ceesay SM, VasquezVelasquez L, Fraser DR (1990) Breast-milk calcium concentrations during prolonged lactation in British and rural Gambian mothers. Acta Paediatr Scand 79:507-512

21. Jarjou LM, Goldberg GR, Coward WA, Prentice A (2012) Calcium intake of rural Gambian infants: a quantitative study of the relative contributions of breast milk and complementary foods at 3 and 12 months of age. Eur J Clin Nutr 66(6):673-677

22. Yan L, Schoenmakers I, Zhou B, Jarjou LM, Smith E, Nigdikar S, Goldberg GR, Prentice A (2009) Ethnic differences in parathyroid hormone secretion and mineral metabolism in response to oral phosphate administration. Bone 45:238-245 